\title{
Synthesis and Characterization of AgNps Using Plant Extracts
}

\author{
R. Surega ${ }^{1}$, B. Anita ${ }^{2}$, S. Ramakrishnan ${ }^{2}$, K. Gunasekaran ${ }^{3}$ and S. Nakkeran ${ }^{4}$ \\ ${ }^{1}$ MTCA, Pudukkotai-622 I02, India \\ ${ }^{2}$ Department of Nematology, TNAU, Coimbatore- 641 003, India \\ ${ }^{3}$ Department of Nano Science and Technology, TNAU, Coimbatore- 641 003, India \\ ${ }^{4}$ Department of Plant Pathology, TNAU, Coimbatore- 641 003, India \\ *Corresponding author
}

\section{A B S T R A C T}

\section{Keywords}

Silver

nanoparticles, green synthesis, $T$.

procumbans, $E$.

hirta and A. indica.

Article Info

Accepted:

15 January 2020

Available Online:

10 February 2020
An attempted was made for the green synthesis of silver nanoparticles using commonly available plants viz., Tridax procumbans, Euphorbia hirta and Azardiract aindica. The plants yielding silver nanoparticles successfully were characterized and compared. It is concluded that the plant source of $T$. procumbans is most preferable for the synthesis of nanoparticles having smallest particle size with spherical shape, crystalline nature, stable silver elemental composition etc.,

\section{Introduction}

Biological methods of nanoparticles synthesis using microorganisms like algae (Lengke et al., 2006), bacteria (Husseiny et al., 2007), fungi (Gajbhiye et al., 2009), actinomycetes (Ahmad et al., 2003) and plant or plant extracts (Sumitra, 2013) have been suggested as possible ecofriendly alternatives to chemical and physical methods. Using plants for nanoparticles synthesis can be advantageous over other biological processes by eliminating the elaborate process of maintaining cell cultures (Shankar et al., 2004). Further the green synthesis of AgNPs using plant sources which does not require the usage of high pressure, energy, temperature and toxic chemicals is considered as cost effective and ecofriendly method by Barrena et al., (2009). Besides, Parikh et al., (2008) and Bar et al., (2009) opined that the green synthesis of nanoparticles can be suitably scaled up for large scale with well-defined size and shape. Moreover the ecofriendly nanoparticles were not reported to produce toxic wastes in the process of synthesizing of 
silver nanoparticles. However, physical and chemical methods used to synthesize metal nanoparticles have certain disadvantages due to involvement of hazardous chemicals, high energy requirements and radiation.

The advantage of using plants for the synthesis of nanoparticles is that they are easily available, safe to handle and possess a broad variability of metabolites that may aid in reduction and to act as capping agent. The size of the nanoparticles synthesized using xerophytes, mesophytes and hydrophytes were in the acceptable range of 2- $50 \mathrm{~nm}$ (Jha et al., 2009).

Hence, Morones et al., (2005) concluded that the green synthesis of AgNPs has offered a consistent, nontoxic and ecofriendly approach for plant pathogen management due to their strong antimicrobial properties.

\section{Materials and Methods}

\section{Preparation of plant extracts}

The healthy fresh leaves of above $T$. procumbens, E. hirta and A. indica were collected from farm area of the Tamil Nadu Agricultural University, Coimbatore. The leaves were thoroughly washed with tap water to remove soil, dirt, etc. and finally with distilled water. Twenty five grams of the leaves were cut into small pieces and taken in $250 \mathrm{ml}$ Erlenmeyer flask containing sterile distilled water and kept in a water bath at $90^{\circ} \mathrm{C}$ for $45 \mathrm{~min}$. The extract was filtered using Whatman filter paper no.1 to obtain the aqueous plant extracts.

\section{Preparation of silver nitrate solution}

The silver nitrate $\left(\mathrm{AgNO}_{3}\right)$ was purchased from Hi-Media Laboratories Pvt. Ltd. was used in the present study. A concentration of $0.01 \mathrm{M} \mathrm{AgNO}_{3}$ solution was prepared by dissolving $0.169 \mathrm{~g} \mathrm{AgNO}_{3}$ in $100 \mathrm{ml}$ double distilled water and used for the green synthesis of silver nanoparticles (AgNPs).

\section{Synthesis of AgNPs}

The above filtered aqueous leaf extracts of 25 $\mathrm{ml}$ was added individually to $100 \mathrm{ml}$ of $0.01 \mathrm{M}$ of $\mathrm{AgNO}_{3}$ in a $250 \mathrm{ml}$ Erlenmeyer flask and boiled at $90^{\circ} \mathrm{C}$ for $10-15 \mathrm{~min}$. Then subsequently content of the flask was stirred at $150 \mathrm{rpm}$ at $30^{\circ} \mathrm{C}$ using magnetic stirrer.

The process was continued till the change of colour occurred from yellowish to dark brown indicating the completion process of AgNPs synthesis. Then the extract was centrifuged at $6000 \mathrm{rpm}$ for $15 \mathrm{~min}$ and the resultant pellet was kept in hot air oven overnight at $60^{\circ} \mathrm{C}$ to make a fine powder of nanoparticles (Dhanalakshmi and Rajendran, 2012).

\section{Characterization of the green synthesized} AgNPs

\section{Particle size analyzer with Zeta potential}

The particle size analyzer (Make: HORIBA Nanoparticle analyzer SZ-100 Japan) was used to measure the size and distribution pattern of green synthesized AgNPs. A sample of $0.5 \mathrm{mg}$ of AgNPs was dispersed in $20 \mathrm{ml}$ distilled water and sonicated for $32 \mathrm{~min}$ (4 cycles) using ultrasonicator make of Citizon Digital Cleaner at $42,000 \mathrm{~Hz}$ frequency and $5 \mathrm{ml}$ of the dispersed AgNPs taken in the cuvette was loaded in the particle size analyzer to determine the size of green synthesized AgNPs.

\section{Stability of particles}

The stability of the AgNPs wasassessed in terms of Zeta potentialusing the above particle size analyzer allowing to run from $200 \mathrm{mV}$ to $+200 \mathrm{mV}$ and plotting the data in graph. 


\section{UV-Vis Spectroscopy}

The UV-Vis spectroscopy was used to confirm the synthesis of AgNPs based on their optical properties. The wavelength of green synthesized AgNPs based on light absorbance in the range of 300 to $600 \mathrm{~nm}$ with resolution of $1 \mathrm{~nm}$ was measured by loading the sample of $2 \mathrm{ml}$ in quartz cuvette in UV-Vis spectroscopy (Make: BeckmanDU20).

\section{Scanning electron microscope (SEM) with EDAX}

The SEM was used to characterize the size and morphology of the nanoparticles by focusing a beam of high-energy electrons to generate a variety of signals at the surface of solid specimen of green synthesized AgNPs. A sample of $0.5 \mathrm{mg} \mathrm{AgNPs}$ was dusted on one side of the double sided adhesive carbon conducting tape. The tape was then mounted on $8 \mathrm{~mm}$ diaaluminium stub. The sample was observed at different magnification and the images were picturized(Make: FEI QUANTA 250, Netherlands).

\section{Transmission electron microscope (TEM) with EDAX}

The TEM was used to image the size and shape of green synthesized AgNPs. A sample of $0.5 \mathrm{mg}$ of AgNPs was dispersed in $20 \mathrm{ml}$ distilled water and sonicated for $32 \mathrm{~min}$ by using Citizon Digital Ultrasonic Cleaner at $42,000 \mathrm{~Hz}$ frequency. A drop of the resultant solution was placed on 300-mesh lacy carbon coated copper grid, dried and the images were captured at different magnifications (Make: FEI TECHNAI SPRIT, Netherlands).

\section{X-Ray diffraction (XRD)}

The result obtained from the XRD pattern was interpreted with standard reference of Joint
Committee on Powder Diffraction Standards (JCPDS card number 04-0783) for the characterization of AgNPs. For XRD analysis, one $g$ of AgNPs was loaded in the sample holder of instrument and allowed to run at 40 $\mathrm{kV}$ voltage and $30 \mathrm{~mA}$ current with $\mathrm{Cu} \mathrm{K}$ (a) radiation for the identification of nature of the particles (Shankar et al., 2004). Then the diffractogram was recorded with $2 \theta$ value ranging between $10-80^{\circ}$ at a scanning speed of 0.080 for a step time of a second at room temperature $\left(25^{\circ} \mathrm{C}\right)$.

\section{Fourier transform infrared spectroscopy (FTIR)}

The FTIR data measures the interaction between Ag and protein molecules. Therefore for FTIR analysis a sample of $0.5 \mathrm{~g}$ of AgNPs was used and the spectra was scanned in the range of $4000-400 \mathrm{~cm}^{-1}$ at a resolution of 4 $\mathrm{cm}^{-1}$ for the characterization of chemical functional groups present over the surface of green synthesized AgNPs.

\section{Results and Discussion}

Comparison of AgNPs based on their characterization

The characters viz., particle size, shape, stability, structure, elemental composition etc. of green synthesised AgNPs using $T$. procumbens, $E$. hirta and $A$. indica were compared. Among them the most effective plant based AgNPs was selected based on desirable characters and advanced for their antimicrobial properties.

\section{Particle size analyser with zeta potential}

The particle size analyzer used to estimate the average particle size of synthesized AgNPs revealed the particle size of $78.9,87.6$ and $40.4 \mathrm{~nm}$ with plant extracts of $T$. procumbens, $E$. hirta and A. indica respectively used for 
the synthesis of AgNPs in the present study. The findings of the present study fall in line with the report of successful synthesis of AgNPs with the plants of $T$. procumbens (Ondari and Nalini, 2014) and A. indica (Gavhane et al., 2012). The environmentally benign and chemically complex nature of plants which contains biomolecules such as proteins, enzymes, amino acids, alkaloids, terpenoids, phenols, flavanoids, tannins, quinines etc., were reported to be responsible for the successful synthesis of AgNPs (Kavitha et al,2013). The AgNPs size of 10 to $60 \mathrm{~nm}$ with spherical shape, stability, crystalline nature, higher content of silver elemental composition were considered as the desirable characters of green synthesized AgNPs (Shah et al., 2009).

\section{Zeta potential}

The Zeta potential was used to measure the physical stability and colloidal systems of synthesized AgNPs was registered as -41.7, 27.9 and $-37.2 \mathrm{mV}$ with $T$. procumbens, $E$. hirta and A. indica respectively.

The Zeta potential distributed with wide range of $-41.7 \mathrm{mV}$ indicated the highly stable in nature of NPs at highest level in the plant source of $T$. procumbans used for the green synthesis of AgNPs. It is reported that the stability of the green synthesized AgNPs is varying markedly (Kavitha et al., 2013).

The finding is contradictory to the earlier report of low to moderate stability of the synthesized AgNPs using $T$. procumbens made by Ondari and Nalini (2014). However, the high stability of AgNPs synthesized using T. procumbens in the present study supported the preference of the same plant source for the synthesis of AgNPs.

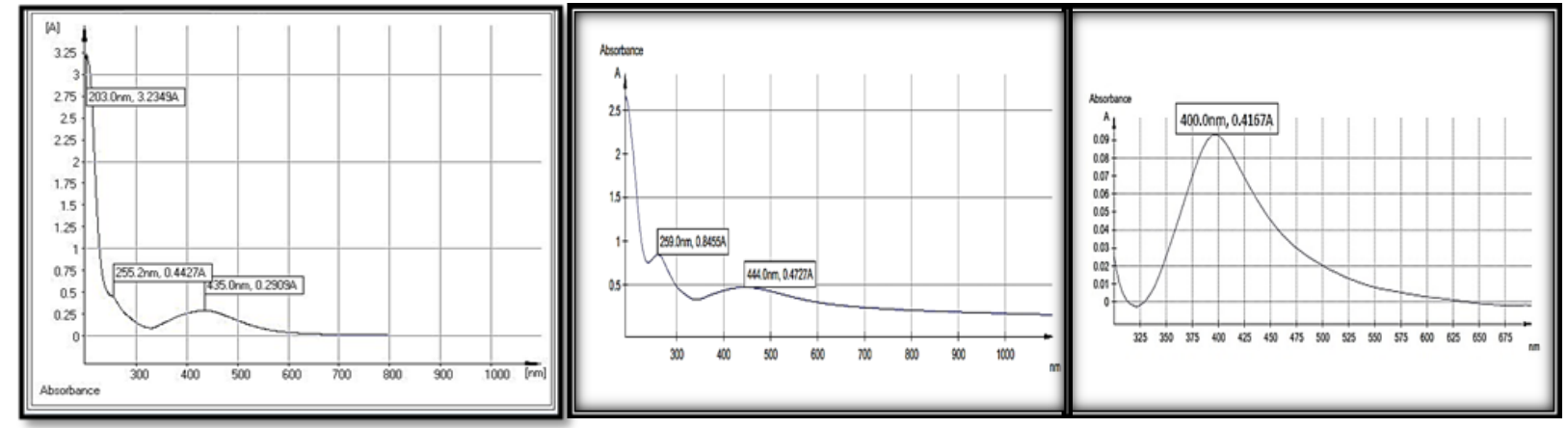

Figure.1 UV-Vis spectra analysis for AgNPs using T.procumbens, E.hirta\& A. indica

\section{$\mathrm{UV}-\mathrm{V}$ is Spectroscopy}

The green synthesized AgNPs initially showed yellowish color in aqueous solution due to excitation of surface plasma resonance of AgNPs. Then the color of the solution changed from yellow to brown on addition of plant extracts to silver nitrate. The color change indicated the formation of AgNPs.Further, it was confirmed with the wavelength of 435,444 and $400 \mathrm{~nm}$ recorded with the plant extracts of $T$. procumbens, $E$. hirta and $A$. indica respectively (Fig. 1). Since the registered wavelength falls within the prescribed range of 430-460 $\mathrm{nm}$ confirmed the formation of AgNPs.

Shankar et al., (2004) reported the confirmation of formation of AgNPs could be made with absorbance peak ranging from 430 to $460 \mathrm{~nm}$. The AgNPs synthesized in the present study using $T$. procumbens had the 
maxima absorbance of $435 \mathrm{~nm}$ which was within the range indicated. Bhati and Malik (2014) and Ondari and Nalini (2014) explained that there was reduction of pure $\mathrm{Ag}^{+}$to $\mathrm{Ag}^{0}$ ions due to splitting of $\mathrm{AgNO}_{3}$ into $\mathrm{Ag}^{+}$and $\mathrm{NO}_{3}{ }^{-}$during the synthesize of AgNPs. Hence change in colour in the reaction mixture was observed with progressive time. Apparently the metabolites in the leaf extract acted as $\mathrm{e}^{-}$donor and reduced $\mathrm{Ag}^{+}$ions into $\mathrm{Ag}$.

\section{Scanning electron microscope (SEM) with EDAX}

The morphology of the synthesized AgNPs using $T$. procumbens, E. hirta and A. indica respectively were observed through SEM. The observations revealed that the AgNPs were spherical in their shape and agglomerated. The EDAX profile showed the highest silver elemental composition of synthesized AgNPs and it was highest (97.91\%) with T. procumbens.

It was followed by $E$. hirta $(86.3 \%)$ and $A$. indica $(78.12 \%)$ respectively. The observations made through SEM revealed spherical shape of the AgNPs using all the above three plants with agglomeration. The observations made through SEM also confirmed the spherical shape of AgNPs. Dhanalakshmi and Rajendran (2012), Bhati and Malik (2014) and Ondari and Nalini (2014) also observed similar spherical shape of green synthesized AgNPs using $T$. procumbens.

The same authors reported that the elongated large spherical nanoparticles as seen with the presently green synthesized AgNPs was due to agglomeration and it was caused by the accumulation of two or more reducing moieties bound on the surface of the preformed nuclei.

\section{Transmission electron microscope (TEM)} with EDAX

The observations made through the TEM revealed the spherical shape of AgNPs with size ranging from 15.5 to $31.8 \mathrm{~nm}, 35$ to 49 $\mathrm{nm}$ and 26.7 to $43.2 \mathrm{~nm}$ in respect of $T$. procumbens, $E$. hirta and $A$. indica respectively (Fig 2). Therefore, it is inferred that the AgNPs size was lowest with $T$. procumbens among the three plant extracts used for the green synthesis of AgNPs. The TEM EDAX observations showed the specified peaks indicating the possession of silver in AgNPs using the above three plant sources (Ondari and Nalini, 2014 and Gavhaneet al., 2012).

Further, the TEM EDAX analysis undertaken to determine the elemental composition also showed that there was highest silver elemental composition $(97.91 \%)$ in $T$. procumbens mediated synthesized AgNPs. The elemental composition of silver was lesser in AgNPs synthesized using certain plants (Khan et al., 2013).Therefore, the higher elemental composition of silver as observed with $T$. procumbens mediated synthesized AgNPs in the present study made the plant as desirable source for the synthesis of AgNPs.

\section{X-Ray diffraction (XRD)}

The X-Ray Diffraction (XRD) pattern profile of all the three plants mediated synthesized AgNPs samples quite consistently matched well with the standard Ag nanopatterns.

The XRD patterns recorded in the $2 \theta$ range of $10-80^{\circ}$ with the synthesized AgNPs indicated the crystalline natureof AgNPs by showing strong diffraction peaks at $28.60^{\circ}, 32.50^{\circ}$, $38.38^{0}, 44.56^{0}, 46.42^{0}, 55.57^{0}, 64.78^{0}$ and $77.02^{0}$ for $T$. procumbens, $27.65^{\circ}, 31.98^{0}$, $37.62^{0}, \quad 45.13^{0}, \quad 53.22^{0}, \quad 55.32^{0}, \quad 61.30^{0}$ 
and71.66 forE. hirta and $27.74^{0}, 32.05^{\circ}$, $26.39^{0}, 45.17^{0}, \quad 52.96^{0}, \quad 55.24^{0}, 61.32^{0}$ and $71.70^{\circ}$ forA. indica. The T. procumbans mediated synthesis of AgNPs showed the maxima at $2 \theta=32.50^{\circ}$ which corresponding to the d spacing of $2.75 \AA$, E. hirta showed the maxima at $2 \theta=31.98^{\circ}$ with corresponding $d$ spacing of $2.76 \AA$ and $A$. indica also showed the maxima at $2 \theta=32.05^{\circ}$ with corresponding d spacing of $2.75 \AA$.

All the above plant extracts exhibited the diffraction pattern which is characteristic to indicate crystalline nature of AgNPs.

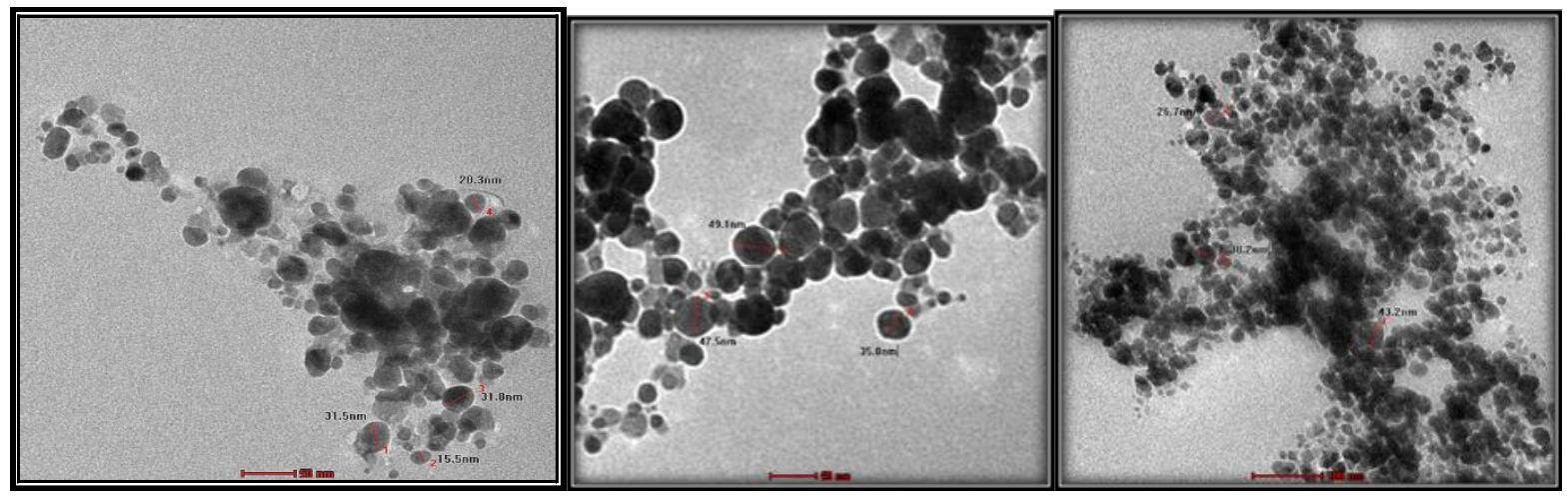

Figure.2 TEM imageofgreen synthesized AgNPs with T. procumbens, E. hirta\& A. indica

The XRD data confirmed that the AgNPs was crystalline in nature as the values matched well with the standard reference of Joint Committee on Powder Diffraction Standards (JCPDS Card No.04-0783) of silver nanoparticles. The sharp and clearly visible peaks of XRD profile confirmed that the particles were crystalline. The sharp peak indicated by the X-ray diffraction pattern confirmed the crystalline nature of green synthesized AgNPs using all the above three plants in the present study and the findings confirmed the earlier report of Shankar et al., (2004); Sileikaite et al., (2009); Geoprincy et al., (2011) and Bhati and Malik (2014).

\section{Fourier transform infrared spectroscopy (FTIR)}

The FTIR spectral analysis showed the presence of possible functional groups of phytochemicals in plant extracts used for the synthesis of AgNPsas per standard reference of Infrared (IR) charts. The synthesized AgNPs using leaf extracts of $T$. procumbens and E. hirta exhibited intense absorption peaks at $867.92,1639.41$ and $3357.90 \mathrm{~cm}^{-1}$ corresponding to strong stretching of $\mathrm{C}-\mathrm{H}$ aromatics. The medium stretching band indicated the presence of $\mathrm{N}-\mathrm{H}$ primary and secondary amides and the broad band denoted as -OH stretching indicated the presence of alcohols and phenols as functional groups of biomolecules of the plant extracts. Similarly A. indica showed the peak at 1641.34, 2360.75 and $3359.83 \mathrm{~cm}^{-1}$ with corresponding medium stretch of $-\mathrm{C}=\mathrm{C}-$ alkenes.

The medium and broad stretching of $\mathrm{H}-\mathrm{C}=\mathrm{O}$ : $\mathrm{C}-\mathrm{H}$ aldehydes and $-\mathrm{OH}$ alcohols and phenols indicated that biomolecules present in the extracts acted as reducing, capping and stabilizing agents for the development of AgNPs. The FTIR analysis confirmed the presence of different functional group of phytochemicals in plants used for the synthesis of AgNPs. The phytochemicals were believed to act as reducing agent for the conversion of $\mathrm{Ag}^{+}$to $\mathrm{Ag}^{0}$ and to act as capping and stabilizing agent of AgNPs in the present study. 
Table.1 Comparison of characters of green synthesized AgNPs using different plants

\begin{tabular}{|c|c|c|c|c|c|}
\hline \multirow[t]{2}{*}{ S.No } & \multirow[t]{2}{*}{ Characters } & \multirow{2}{*}{$\begin{array}{l}\text { Instruments } \\
\text { used }\end{array}$} & \multicolumn{3}{|c|}{ Plants } \\
\hline & & & T. procumbens & E. hirta & A.indica \\
\hline 1 & Particle size & $\begin{array}{c}\text { Particle Size } \\
\text { Analyzer }\end{array}$ & $78.9 \mathrm{~nm}$ & $87.6 \mathrm{~nm}$ & $40.4 \mathrm{~nm}$ \\
\hline 2 & Particle stability & Zeta potential & $-41.7 \mathrm{mV}$ & $-27.9 \mathrm{mV}$ & $-37.2 \mathrm{mV}$ \\
\hline 3 & $\begin{array}{l}\text { Confirmation of } \\
\text { AgNPs synthesis }\end{array}$ & $\begin{array}{c}\text { Uv-Vis } \\
\text { Spectroscopy }\end{array}$ & $\begin{array}{l}\text { Confirmed with } \\
\text { absorbance peak } \\
\text { at } 435 \mathrm{~nm}\end{array}$ & $\begin{array}{c}\text { Confirmed with } \\
\text { absorbance at } 444 \\
\text { nm }\end{array}$ & $\begin{array}{c}\text { Confirmed with } \\
\text { absorbance at } 400 \\
\mathrm{~nm}\end{array}$ \\
\hline \multirow[t]{2}{*}{4} & Shape & SEM & \multicolumn{3}{|c|}{ Spherical with agglomeration } \\
\hline & & TEM & $\begin{array}{l}\text { Spherical with } \\
\text { size of } \\
15.5-31.8 \mathrm{~nm}\end{array}$ & $\begin{array}{l}\text { Spherical with } \\
\text { size of } \\
35-49 \mathrm{~nm}\end{array}$ & $\begin{array}{l}\text { Spherical with } \\
\text { size of } \\
26.7-43.2 \mathrm{~nm}\end{array}$ \\
\hline 5 & $\begin{array}{l}\text { Silver elemental } \\
\text { composition }(\%)\end{array}$ & SEM (EDAX) & 97.91 & 86.83 & 78.12 \\
\hline 6 & Nature of particles & XRD & \multicolumn{3}{|c|}{ Crystalline } \\
\hline
\end{tabular}

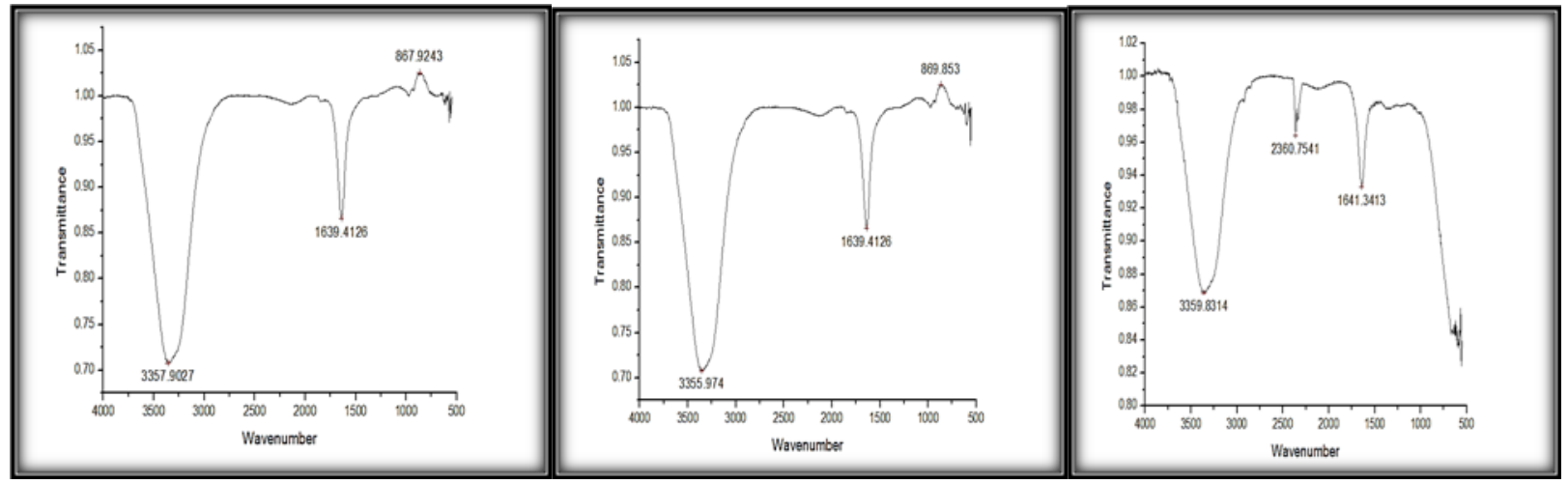

Figure.3 FTIR spectral analysisof synthesized AgNPs in T. procumbans, E. hirta\&A. indica

The findings support the earlier reports of Tripathy et al., (2010); AbduzZahir et al., (2012); Ondari and Nalini (2014) and Bhati and Malik (2014). In this regard the above authors speculated that the phytochemicals viz., phenols, aldehydes, aromatic groupsof the amino acid residues and proteins had strong ability to bind with metal for acting as reducing, capping and stabilizing agent of green synthesized AgNPs. Further, it is reported to be responsible for the prevention of agglomeration of green synthesized AgNPs. Therefore, it is concluded that the phytochemicals/biomolecules present in the above plant sources played a dual role in the formation and stabilization of the green synthesized AgNPs. Among the three plants chosen for the synthesis of AgNPs the $T$. procumbens was considered as most preferable plant source owing to the following reasons. As per particle size analyzer the average particle size of AgNPs was within the limit of $100 \mathrm{~nm}$ (Ravikumar and Sathish Kumar, 2014)viz.,T. procumbens $(78.9 \mathrm{~nm})$, E. hirta $(87.6 \mathrm{~nm})$ and A. indica $(40.4 \mathrm{~nm})$ used for the green synthesis of AgNPs.

Whereas the particle size of AgNPs using $T$. 
procumbens was found to be the least (15.5 to $31.8 \mathrm{~nm}$ ) as per the TEM observations in the present study and it is coinciding with the report of Nagati et al., (2012) who stated that the size of synthesized AgNPs within $50 \mathrm{~nm}$ could be optimum size for silver nanoparticles.

The smallest size of nanoparticles having the highest surface volume ratio which enhance the surface energy is lethal to biological organisms as reported by Shrivastava et al., (2007). Therefore, the $T$. procumbens is highly preferred than other plant sources tried for the green synthesis of AgNPs.

\section{References}

Abduz Zahir, A., Bagavan, A. Kamaraj, C. Elango G. and Abdul Rahuman, A. 2012. Efficacy of plant mediated synthesized silver nanoparticles against Sitrophilus oryzae. Journal of Biopesticides.5: 95 102.

Ahmad, A., Mukherjee, P, Senapati, S,Mandal, D,Khan, M.I.,Kumar R. and Sastry,M. 2003. Extracellular biosynthesis of silver nanoparticles using the fungus Fusarium oxysporum. Colloids Surf. B: Biointerfaces.28: 313-318.

Bar, H., Bhui, D. K., Sahoo, G. P., Sarkar, P., De S. P. and Misra, A. 2009. Green synthesis of silver nanoparticles using latex of Jatropha curcas. Colloids Surf A: Physicochem. Eng. Asp.339: 134-139.

Barrena, R., Casals, E.,Colon, J.,Font, X., Sanchez,A. and Puntes,V. 2009. Evaluation of the ecotoxicity of model nanoparticles. Chemosphere.75: 850-857.

Bhati, H. and Malik,C.P. 2014.Biosynthesis of silver nanoparticles using fresh extracts of Tridax procumbens Linn. Indian Journal of Experimental Biology.52: 359368.

Dhanalakshmi, R. and Rajendran,S. 2012. Synthesis of silver nanoparticles using
Tridaxprocumbens and its antimicrobial activity. Arch. Applied Sci. Res. 4: 12891293.

Gajbhiye, M., Kesharwani,J., Ingle, A., Gade, A. and Rai,M.2009. Fungus mediated synthesis of silver nanoparticles and its activity against pathogenic fungi in combination of fluconazole. Nanomedicine.5(4): 282-286.

Gavhane, A.J., Padmanabhan, P., Kamble,S.P. and Jangle,S.N. 2012. Synthesis of silver nanoparticles using extract of neem leaf and triphala and evaluation of their antimicrobial activities.International Journal of Pharma and Biosciences.3(3): 88 - 100.

Geoprincy, G., Saravanan, P.,Nagendra,N. and Renganathan,S.2011. A novel approach of studying the combined antimicrobial effects of silver nanoparticles and antibiotics through agar over layer method and disc diffusion method. Dig. J. Nanomat. Bios.6(4): 1557-1565.

Husseiny, M.I., El-Aziz, M.A.,BadrY.and Mahmoud,M.A. 2007. Biosynthesis of gold nanoparticles using Pseudomonas aeruginosa. SpectrochimicaActa A: Mol. Biomol. Spectrosc. 67: 1003-1006.

Jha, A.K., Prasad,K. and Prasad,D.2009. A green low-cost biosynthesis of Sb20 nanoparticles. Biochem. Eng. J.43: 303306.

Kavitha, K.S., Baker, S., Rakshith, D., Kavitha, H.U.,Yashwantha Rao,H.C., Harini,B.P. and Satish,S. 2013. Plants as green source towards synthesis of nanoparticles. International Research Journal of Biological Sciences.2(6): 6676.

Khan, M., Khan, M.,Adil, S.F.,Tahir, M.N.,Tremel, W.,Alkhathlan,H.Z. and Siddiqui,H. 2013. Green synthesis of silver nanoparticles mediated by Pulicaria glutinosa extract. International Journal of Nanomedicine.8: 1507-1516. 
Lengke, M., Fleet,M.E. and Southam,G.2006. Morphology of gold nanoparticles synthesized by filamentous cyanobacteria from gold (I)-thiosulfate and gold (III)chloride complexes. Langmuir.22: 27802787.

Morones, J.R., Elechiguerra, J.L.,Camacho, A.,Holt, K., Kouri, J.B.,Ramfrez,J.T. and Yacaman, M.J. 2005. The bactericidal effect of silver nanoparticles. Nanotechnology.

16: 2346-2353.

Nagati, V.B., Alwala, J., Koyyati, R., Donda, M.R., BanalaR. and Padigya,P.R.M. 2012. Green synthesis of plant mediated silver nanoparticles using Withania somnifera leaf extract and evaluation of their antimicrobial activity. Asian Pacific Journal of Tropical Biomedicine.14:1-5.

Ondari, N.E. and Nalini,M.P. 2014. Antimicrobial activity of biogenic silver nanoparticles synthesized using Tridaxprocumbens L. Int. J. Curr. Res. Aca. Rev., 2(7): 32-40.

Parikh, R.Y., Singh, S., Prasad, B.L. V., Patole, M.S., Sastry,M. and Shouche,Y.S. 2008. Extracellular synthesis of crystalline silver nanoparticles and molecular evidence of silver resistance from Morganella sp.: Towards understanding biochemical synthesis mechanism. Chem. Biochem. 9: 1415-1422.

Ravikumar, P. and Sathish Kumar,S. 2014. Antifungal activity of extracellularly synthesized silver nanoparticles from Morinda citrifolia L. International
Journal of Technical Research and Applications.2 (4): 108-111.

Shah, S.N., Steinmetz, N.F.,Aljabali, A.A.,Lomonossoff,G.P. and Evans,D.J 2009. Environmentally benign synthesis of virus template, monodisperse, iron plantinum nanoparticles. Dalton Trans. 40: 8479-8480.

Shankar, S.S., Rai, A., Ankamwar, B., Singh, A.Ahmad,A. and Sastry,M. 2004. Rapid synthesis of $\mathrm{Au}, \mathrm{Ag}$, and bimetallic $\mathrm{Au}$ core-Ag shell nanoparticles using Neem (Azadirachta indica) leaf broth. Journal of Colloid and Interface Science.275 (2): 496-502

Shrivastava, S., Bera, T., Roy, A., Gajendra Singh, Ramachandrarao,P. and Dash,D. 2007. Characterization of enhanced antibacterial effects of novel silver nanoparticles. Nanotechnology. 18: 1-9.

Sileikaite, A., Judita, P., Igoris,P. and Sigitas,T. 2009. Investigation of silver nanoparticles formation kinetics during reduction of silver nitrate with sodium citrate. Materials Science.15: 21-27.

Sumitra, C. 2013. Silver nanoparticles (medicinal plants mediated): A new generation of antimicrobials to combat microbial pathogens- A review. Formatex.13: 1314-1323.

Tripathy, A., Raichur, M.A.,Chandrasekaran, N., Prathna,T.C. and Mukherjee,A. 2010. Process variables in biomimetic synthesis of silver nanoparticles by aqueous extract of Azadirachta indica (Neem) leaves. Journal of Nano Research.12(1): 237-246.

\section{How to cite this article:}

Surega. R., B. Anita, S. Ramakrishnan, K. Gunasekaran and Nakkeran. S. 2020. Synthesis and Characterization of AgNps Using Plant Extracts. Int.J.Curr.Microbiol.App.Sci. 9(02): 19391947 doi: https://doi.org/10.20546/ijcmas.2020.902.221 